\title{
Some Properties of Aluminium and its Alloys \\ Paris Meeting of the Institute of Metals
}

$\mathrm{A}^{\mathrm{T}}$

$\mathrm{T}$ the invitation of the Bureau International des Applications de l'Aluminium, the autumn meeting of the Institute of Metals was this year held in Paris, on September 14-19. As a natural consequence of this invitation, the majority of the papers presented for discussion at this meeting dealt with various aspects of the metallurgy of aluminium and its alloys.

\section{Conductivity of Aluminium}

The first paper presented, by M. Gaston Gauthier, dealt with the conductivity of super-purity aluminium and the influence of small metallic additions. The

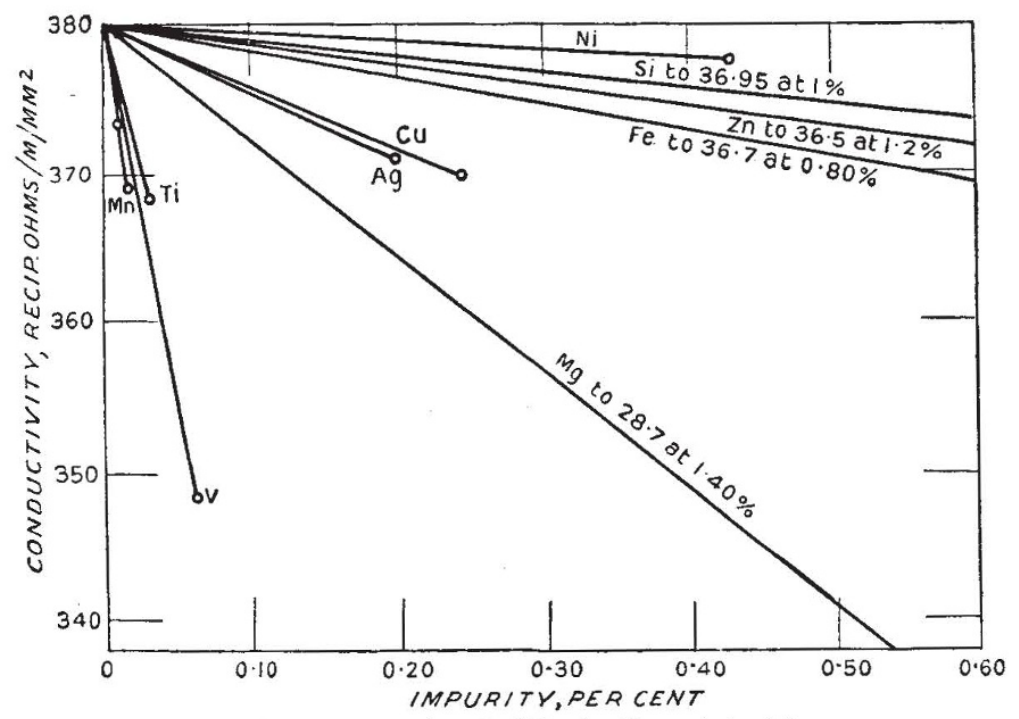

Fig. 1. Mean decrease of conductivity in alloys of aluminium as a function of the content of alloying element added.

aluminium employed in the investigation exceeded $99 \cdot 99$ per cent purity, and the added elements were those which may occur as impurities in commercial aluminium. The high purity of the basis metal made it possible to determine accurately the effect of each one of the added elements in the almost complete absence of other impurities. The accompanying diagram (Fig. 1) summarizes the results; it shows the average decrease of conductivity brought about by the various elements within the limits investigated. It is possible to divide the elements into three groups :

(1) Gold, gallium, nickel, silicon, iron and zine, all of which have little effect.

(2) Copper, silver and magnesium, which have rather more effect.

(3) Titanium, vanadium, manganese and chromium, all of which exert a considerable effect.

In spite of the precautions taken in preparing his samples, the author's figures do not support Norbury's law, to the effect that the increase in resistivity brought about by the addition of the same number of atoms is larger, the greater the separation between the added element and the basis metal in the periodic system. M. Gauthier is considering whether another generalization cannot be established.

\section{INDIRECT FACTORS}

Between the initial development of a light alloy and its general utilization in industry there is usually encountered a number of unsuspected and troublesome factors. The Marquis de Fleury, assisted by Dr. H. Portier, presented an analytical study of these factors and the laws governing them in the course of a paper entitled "The Complex Interdependence of the Properties of Alloys and the Industrial Conditions of their Manufacture, Testing and Use". Factors which are apparently unrelated are shown to be actually so interdependent that a simple modification of one can upset the equilibrium of the whole cycle of the life of a casting. This interdependence has been studied in the particular case of aluminium alloys, although the problem is, of course, the same for all metals. Metallurgists are warned against the unconsidered application of new alloys, and engineers against hasty condemnation of the materials with which they are supplied. In spite of careful forethought, unsuitable applications will be encountered which will throw a prematurely advertised material into disfavour; this is the explanation, according to the authors, of the amazing setbacks to be remembered in the history of the most logical developments.

\section{Properties AFTER PROLONGED HEATING}

An investigation of the strength of pure aluminium and various aluminium alloys after heating for long periods at $75^{\circ}-300^{\circ} \mathrm{C}$. was described by Prof. A. von Zeerleder and Dr. R. Irmann. The strength properties of these materials were also determined in the state of complete stabilization. The heating periods employed extended over approximately two years. After treatments of different duration at elevated temperatures, some specimens were cooled and tested at room temperature, others being tested at the treatment temperature. For complete softening at $250^{\circ} \mathrm{C}$., for example (that is, to obtain the properties observed in completely stabilized samples), heating periods of at least six months are required in the case of pure aluminium and Anticorodal, and of more than two years for Avional and ' $\mathrm{Y}$ ' alloy. A still longer heating time is necessary in the case of the alloy 'R.R. 59'. To determine the decrease in strength of any material after heating for long periods at elevated temperatures it is necessary, therefore, to carry out tests of long duration.

The values of the yield-point observed in the normal short time test after heating periods of one year form a basis for calculations for engineers. The permissible loads can be ascertained only by observa. tion of the creep limit, and this property is being studied by the authors. 


\section{Aluminium Reflectors}

It is well known that the power to reffect incident light is possessed by various metal surfaces to a very varying degree even when such surfaces have been reduced to the same condition so far as possible by grinding, polishing, etc. Not only does the reflectivity vary over the visible range taken as a whole, but it also varies for different wave-lengths and not always in the same manner. The reflectivity of a silver mirror, for example, is very high when measured on the longer waves, but decreases to almost vanishing point over a narrow band in the ultra-violet. In a paper presented by Mr. N. D. Pullen, a description is given of a dual anodic process designed for the treatment of aluminium surfaces in order to produce a high degree of reflectivity. The first bath, in which the electrolytic brightening is produced, is a mixture of sodium carbonate and sodium phosphate in the approximate proportions of $3: 1$ having a strongly alkaline reaction. The second bath, in which a reinforcing film is produced, consists preferably of a strong solution of acid sodium sulphate. Data are given showing the reflectivity of aluminium surfaces treated by this method compared with a standard silver mirror and other surfaces such as chromium plate, nickel plate, etc.

\section{The Fundamentals of Forging}

All metallurgists are familiar with Prof. Portevin's methods of treating the practical problems of industry in a fundamental manner. The complex properties of castability and weldability have been greatly elucidated by his publications in the past, and now, together with his colleague Dr. Paul Bastien, he has applied the same method of treatment to the study of forgeability. In their paper, "Study of the Forgeability of Various Light and Ultra-Light Alloys", the authors have endeavoured to determine, by means of laboratory tests, the optimum conditions for hot-working. With this in view they have compared the results obtained from static bending and compression tests and dynamic bending and tensile tests. They have indicated the important part played by the rate of deformation, and have shown that the bending test appears to be the most convenient, speedy and sensitive. The tests were carried out on aluminium; on copper-aluminium alloys containing 6 and 12 per cent of copper; on aluminium-magnesium alloys containing 5, 10 and 15 per cent of magnesium ; on magnesium; on magnesium-copper alloys containing 5, 10 and 15 per cent of copper; and on magnesium-aluminium alloys containing 3,6 and 9 per cent of aluminium. The methods of testing employed have made it possible to define the capacity for hot-work of these various alloys.

\section{International Quaternary Association}

\section{CONFERENCE IN VienNA}

$\mathrm{T}^{\mathrm{H}}$ HE Third Conference of the International Quaternary Association (INQUA.) was held in Vienna on September 1-8 under the patronage of Dr. Kurt von Schuschnigg, the Austrian Chancellor, and Dr. Hans Pernter, Minister of Education. Dr. Otto Ampferer, director of the Geologisches Bundesanstalt in Vienna, who is well known for his researches on the interglacial gravels of the Alps, presided over the Organization Committee, and Dr. Gustav Gotzinger was president of the meeting. To these latter and to the genial and multi-lingual secretary, Dr. Helmut Gams of the University of Innsbrück, the meeting owed its undoubted success. That the attendance far exceeded expectations may partly be ascribed to the opportunity of hearing the veteran Prof. Albrecht Penck, who acted as honorary president and spoke on most of the subjects discussed during the Congress.

The geographical situation of Vienna is ideal for such a conference, being accessible without undue travelling to most European nations. To those from the west, the opportunity of seeing a country which, during Quaternary times, took on the character of a pronounced steppe, was a great temptation, and the thick loess deposits of the Austrian Weinviertel north of the Danube eame in for much attention. Here in both fossil and recent examples it was possible to study two of the climatically controlled soil types which the researches of Russian scientific investigators have recently brought into prominence, namely, the black-earth or chernozem which margins the steppes, and the brown-earth or forest soil of the betterwatered areas. This utilization of the physical character and colour of the soil to interpret the climatic conditions under which it was formed is a novelty to glacialists from the leached podsol areas of the north-west, and seems to afford a subtle and useful criterion of changing climate. The main fossil soil zone of the Austrian sections lying between the Younger and Older Loess is locally dated by archæological finds of Aurignacian type just above it, and is therefore presumably of interglacial or RissWurm age, the loess being glacial. These sections were ably demonstrated by Dr. Gotzinger, who, with others, wrote a descriptive guide book for the Congress.

During the visit to Krems, a halt was made at Spitz in order to be present at the unveiling of the memorial to Josef Beyer, the celebrated Austrian archæologist. On a subsequent visit to Eggenburg, Beyer's collections were inspected in the museum, and those who visited this town will long remember the hospitality of its inhabitants. An excursion in the Austrian Alps on September 9-23 was largely attended and enabled the participators to see the terraces and moraines of the quaternary glaciers and a number of interglacial deposits, including the famous Hotting breccia.

The difficulties of language were keenly felt by many members of the Congress. Most of the papers were delivered in German, but, one understands, not always in German as spoken north of the Danube. Many were read from manuscript at undue length and at a speed which made them unintelligible to foreigners. It is surely possible to find some cure for this. Much would be gained if authors would make a point of reading their papers in abridged form in some language other than their own. This 